

Faletehan Health Journal, 6 (3) (2019) 111-117

www. journal.Ippm-stikesfa.ac.id/ojs/index.php/FHJ

ISSN 2088-673X | e-ISSN 2597-8667

\title{
Determinan Sosial Terhadap Tingkat Literasi Kesehatan Pada Pasien Hipertensi di Puskesmas Kota Cilegon
}

\author{
Sahroni $^{{ }^{*}}$, Dien anshari ${ }^{1}$, Tri Krianto ${ }^{1}$ \\ ${ }^{1}$ Fakultas Kesehatan M asyarakat, Universitas Indonesia \\ *Corresponding Author: fayyaza.sahroni@gmail.com
}

\begin{abstract}
Abstrak
Tingkat literasi kesehatan rendah akan menghadapi lebih banyak tantangan saat mengakses dan menggunakan sistem pelayanan kesehatan dan sering dikaitkan dengan hasil kesehatan yang merugikan. Penelitian ini bertujuan untuk mengetahui determinan sosial yang mempengaruhi tingkat literasi kesehatan pada pasien hipertensi di Kota Cilegon, Banten. Desain penelitian menggunakan disain potong lintang, penelitian ini mengambil data dari pasien hipertensi di 8 puskesmas Kota Cilegon $(n=138$ ). Pengukuran literasi kesehatan dilakukan menggunakan instrumen Health Literacy Scale European Union dengan 16 pertanyaan yang telah diadaptasi. Analisis dilakukan menggunakan model regresi linier ganda dengan literasi kesehatan sebagai variabel dependen dan determinan sosial seperti jenis kelamin, kelompok usia, pendidikan, penghasilan, dan pekerjaan sebagai variabel independen. Hasil penelitian menunjukkan rerata skor literasi kesehatan pada penderita hipertensi adalah $58.4(S D=14.2)$ dari skala 100. Hasil analisis regresi linier ganda menunjukkan hubungan yang bermakna antara skor literasi kesehatan dengan usia ( $\beta=6.1, S E=1.8, p=0.01$ ), pendidikan $(\beta=12.5, S E=2.7, p<0.001)$, dan penghasilan $(\beta=9.1, S E=2.2, p<0.001)$. Hasil ini mengindikasikan perlunya penanganan ekstra pada penderita hipertensi yang berusia lanjut, berpendidikan kurang dari SM A, dan berpenghasilan di bawah upah minimum regional.
\end{abstract}

Kata Kunci: Determinan Sosial, Hipertensi, Literasi Kesehatan

\begin{abstract}
Low levels of health literacy will face more challenges when accessing and using health care systems and are often associated with adverse health outcomes. This study aimed to assess social determinants for health literacy among hypertension patients in Cilegon, the capital city of Banten Province, Indonesia. This design used cross sectional study were collected using face to face interviews with quota based samples from registered patients of 8 public health centers $(n=138)$. M ultiple regression was conducted to assess the association of health literacy and social determinants (i.e., sex, age, education, income, and employment status). Univariate analysis showed that the average score of health literacy was $58.4(\mathrm{SD}=14.2$ ) on a scale of 100 . Bivariate analysis showed positive associations between health literacy with all independent variables, except for sex and employment status. Multiple linear regression showed that patients' health literacy was significantly associated with age $(\beta=6.1, \mathrm{SE}=1.8, \mathrm{p}=0.01)$, education ( $\beta=12.5, \mathrm{SE}=2.7, \mathrm{p} \varangle 0.001)$, and income $(\beta=9.1, \mathrm{SE}=2.2, \mathrm{p}<0.001)$. Results showed that doctors and health care workers need to provide extra treatment for hypertension patients who are older, have education below high school, and have limited income.

Keywords: Health literacy, Hypertension, Social Determinants
\end{abstract}




\section{Pendahuluan}

Literasi kesehatan adalah tingkat kemampuan individu dalam memperoleh, memproses dan mengerti suatu dasar informasi kesehatan dan pelayanan kesehatan yang dibutuhkan untuk membuat suatu keputusan tepat terkait kesehatannya (Institute of Medicine of The National Academic, 2012). Sampai saat ini tingkat literasi kesehatan masih menjadi masalah baik di negara maju maupun berkembang. Survei yang dilakukan di Taiwan pada tahun 2010 memberikan hasil sekitar 30,3\% penduduk dewasa memiliki literasi kesehatan yang kurang (Lee, Tsai dan Kuo, 2010). Penelitian yang sama seperti studi di Turki memberikan hasil $71,9 \%$ responden memiliki tingkat literasi kesehatan yang rendah (Ozdemir dkk, 2010).

Di Indonesia penelitian mengenai tingkat literasi kesehatan masyarakat masih terbatas, terutama pada kelompok-kelompok masyarakat tertentu (kelompok penderita hipertensi). Penelitian yang dilakukan Soemitro (2014) memberikan gambaran tingkat literasi kesehatan pada penderita hipertensi di Puskesmas Kabupaten Malang sebagian besar memiliki tingkat literasi yang buruk sebesar $65,35 \%$. Hal yang sama diperkuat lagi dengan penelitian Fitriyah (2017) memberikan gambaran literasi kesehatan penderita penyakit kronis TB Paru di Kabupaten Sumenep masuk dalam kategori sedang dan rendah (Soemitro, 2014; Fitriyah, 2017). Berbagai penelitian menunjukan bahwa literasi kesehatan merupakan salah satu prediktor terkuat untuk kesehatan seseorang. Tingkat literasi kesehatan yang rendah berhubungan dengan kurangnya pengetahuan mengenai tindakan kesehatan yang bersifat pencegahan, perawatan diri dan pengobatan. Pengetahuan yang kurang ini bervariasi mulai dari pengetahuan demam pada anak hingga keadaan yang kronis seperti hipertensi dan diabetes. Beberapa contoh adalah penderita hipertensi tidak mengetahui bahwa penurunan berat badan dan olah raga dapat membantu mengontrol hipertensi (Weiss, 2007).

Hipertensi adalah kondisi yang kompleks dimana tekanan darah secara menetap berada di atas normal. Kriteria hipertensi yang digunakan pada penetapan kasus merujuk pada kriteria diagnosis JNC VII 2003, yaitu hasil pengukuran tekanan darah sistolik $\geq 140 \mathrm{mmHg}$ atau tekanan darah diastolik $\geq 90 \quad \mathrm{mmHg}$ (Kementerian
Kesehatan, 2013). Hipertensi sering tidak menimbulkan gejala sehingga disebut juga sebagai silent killer karena tekanan darah yang terus menerus tinggi dalam jangka waktu lama dapat menimbulkan komplikasi yang mematikan.

Menurut World Health Organization (WHO), hipertensi memberikan kontribusi untuk hampir 9,4 juta kematian akibat penyakit kardiovaskuler setiap tahun. Hal ini juga meningkatkan risiko penyakit jantung koroner sebesar $12 \%$ dan meningkatkan risiko stroke sebesar 24\%. Data Global Status Report on Noncommunicable Diseases 2010 dari WHO, menyebutkan 40\% negara ekonomi berkembang memiliki penderita hipertensi, sedangkan negara maju hanya $35 \%$. Di kawasan Asia Tenggara terdapat $36 \%$ orang dewasa yang menderita hipertensi dan menyebabkan kematian 1,5 juta orang setiap tahunnya. Jumlah penderita hipertensi akan terus meningkat dan diprediksikan pada tahun 2025 sekitar 29\% atau sekitar 1,6 miliar orang dewasa di seluruh dunia menderita hipertensi (World Health Organization, 2015).

Menurut hasil Riset Kesehatan Dasar (Riskesdas), prevalensi hipertensi di Indonesia yang didapat melalui pengukuran tekanan darah pada penduduk umur $>18$ tahun mengalami peningkatan dari 25,8\% pada Riskesdas pada 2013 menjadi 34,1\% pada Riskesdas 2018. Selain itu, diagnosis melalui riwayat minum obat hanya mendapatkan hasil sebesar $8,8 \%$ yang menandakan sebagian besar kasus hipertensi di masyarakat belum terdiagnosis dan belum terjangkau pelayanan kesehatan (Badan Penelitian dan Pengembangan Kesehatan, 2018). Profil kesehatan Kota Cilegon tahun 2017 menyebutkan kasus tertinggi PTM adalah kelompok penyakit jantung dan pembuluh darah, khususnya pada kelompok hipertensi esensial, yaitu sebanyak 1.230 orang $(27,5 \%)$ pada kasus baru dan 4.855 orang (29\%) pada kasus lama dari total kasus PTM. Prevalensi hipertensi di Kota Cilegon mencapai $25,6 \%$ dengan rasio kematian karena hipertensi sebesar 0,72\% (Dinas Kesehatan Kota Cilegon, 2017). Meningkatnya kasus hipertensi di Kota Cilegon mengindikasikan rendahnya literasi kesehatan pada penderitanya. Namun, sampai penelitian ini dilakukan, belum pernah ada penelitian yang melihat tingkat literasi kesehatan pada penderita hipertensi di Kota Cilegon. Karena itu, penelitian pada pasien hipertensi di Puskesmas Kota Cilegon ini bertujuan 
Faletehan Health Journal, 6 (3) (2019) 111-117 www. journal.Ippm-stikesfa.ac.id/ojs/index.php/FHJ ISSN 2088-673X | e-ISSN 2597-8667

untuk mengetahui tingkat literasi kesehatan dan determinan sosial yang mempengaruhinya.

\section{Metode Penelitian}

Penelitian ini menggunakan disain potong lintang (cross-sectional) yang mengambil data primer melalui wawancara tatap muka pada pasien hipertensi dari 8 puskesmas di wilayah Kota Cilegon ( $\mathrm{n}=138)$. Sampel diambil dengan teknik probabilitas menggunakan kuota dari buku register di Puskesmas Cibeber, Puskesmas Jombang, Puskesmas Cilegon, Puskesmas Citangkil, Puskesmas Purwakarta, Puskesmas Grogol, Puskesmas Ciwandan dan Puskesmas Pulo Merak pada bulan Februari 2019. Kriteria inklusi sampel adalah pasien hipertensi berusia $\geq 45$ tahun yang tercatat dibuku register rawat jalan dan pasien hipertensi dengan status pasien lama (kunjungan $>2 \mathrm{x}$ dengan diagnosa hipertensi). Sedangkan kriteria eksklusi sampel adalah pasien hipertensi yang sedang hamil, atau yang mengalami komplikasi, atau yang memiliki gangguan kognitif.

Literasi kesehatan diukur menggunakan Health Literacy Scale European Union 16 Questions (HLS-EU-Q16) yang terdiri dari 16 pertanyaan (Storms dkk, 2017) dan telah diadaptasi ke dalam Bahasa Indonesia oleh penelitian terdahulu (Nasriyanto, 2018). Keenam belas pertanyaan memiliki pilihan jawaban dengan skala Likert yang merentang dari 1 (sangat tidak setuju) hingga 4 (sangat setuju). Hasil uji reliabilitas pada instrumen ini menunjukkan nilai konsistensi internal yang baik (Alpha Cronbach $=0.95$ ). Skor dari instrumen literasi kesehatan ditransformasi ke dalam skala 0-100 dengan nilai makin tinggi makin baik.

Variabel independen dalam penelitian ini adalah faktor-faktor demografi yang berkaitan dengan determinan sosial kesehatan seperti jenis kelamin, usia, tingkat pendidikan, status pekerjaan dan tingkat penghasilan. Hubungan antar variabel dependen dan independen dianalisis secara bivariat. Kemudian, uji regresi linier berganda dilakukan melalui pemodelan (Hastono, 2016) dengan hanya menyertakan hasil uji bivariat yang signfikan sehingga dapat menjelaskan hubungan antara literasi kesehatan dengan determinan sosial.

\section{Hasil dan Pembahasan}

Tabel 1 memaparkan bahwa dari 138 pasien hipertensi yang menjadi responden penelitian, sebagian besar adalah perempuan $(79,7 \%)$, berpendidikan sebatas tamat SMP atau di bawahnya $(73,9 \%)$, tidak memiliki pekerjaan $(76,8 \%)$, dan mempunyai penghasilan keluarga di bawah upah minimum regional (UMR) Kota Cilegon $(68,1 \%)$. Besarnya proporsi sampel yang tergolong dalam kelas menengah ke bawah ini disebabkan karena penelitian ini mengambil data dari pasien hipertensi yang terdaftar di puskesmas yang memang umumnya melayani pasien dari kelas menengah ke bawah. Berdasarkan kelompok usia, responden yang termasuk kelompok usia dewasa (45-55 tahun) seimbang jumlahnya dengan yang termasuk kelompok usia lanjut (lebih dari 55 tahun).

Tabel 1. Karakteristik sampel berdasarkan determinan sosial $(\mathrm{n}=138)$

\begin{tabular}{|c|c|c|}
\hline Variabel Independen & $\mathbf{n}$ & $\%$ \\
\hline \multicolumn{3}{|l|}{ Jenis Kelamin } \\
\hline Laki-laki & 28 & 20.3 \\
\hline Perempuan & 110 & 79.7 \\
\hline \multicolumn{3}{|l|}{ Kelompok Usia } \\
\hline Dewasa (45-55 th) & 70 & 50.7 \\
\hline Lanjut (>55 tahun) & 68 & 49.3 \\
\hline \multicolumn{3}{|l|}{ Tingkat Pendidikan } \\
\hline Rendah ( $\leq$ SMP) & 102 & 73.9 \\
\hline Tinggi ( $\geq$ SMA) & 36 & 26.1 \\
\hline \multicolumn{3}{|l|}{ Status Pekerjaan } \\
\hline Tidak bekerja & 106 & 76.8 \\
\hline Bekerja & 32 & 23.2 \\
\hline \multirow{2}{*}{\multicolumn{3}{|c|}{$\begin{array}{l}\text { Tingkat Penghasilan } \\
\text { Keluarga }\end{array}$}} \\
\hline & & \\
\hline Rendah $(\leq$ UMR & 94 & 8.1 \\
\hline \multicolumn{3}{|l|}{ Kota Cilegon) } \\
\hline Tinggi ( $\geq$ UMR & 44 & 31.9 \\
\hline Kota Cilegon) & & \\
\hline
\end{tabular}


Faletehan Health Journal, 6 (3) (2019) 111-117

www. journal.Ippm-stikesfa.ac.id/ojs/index.php/FHJ

ISSN 2088-673X | e- ISSN 2597-8667

Tabel 2. Tingkat Literasi Kesehatan berdasarkan Pertanyaan

\begin{tabular}{|c|c|c|c|}
\hline No & Pertanyaan & Mean & SD \\
\hline 1 & $\begin{array}{l}\text { Mencari informasi tentang bagaimana cara mengobati } \\
\text { penyakit tertentu? }\end{array}$ & 56.76 & 21.46 \\
\hline 2 & $\begin{array}{l}\text { Mencari tahu ke mana harus pergi untuk mendapatkan } \\
\text { bantuan professional saat anda sakit? }\end{array}$ & 69.32 & 19.34 \\
\hline 3 & Memahami apa yang dikatakan oleh dokter kepada anda? & 63.76 & 17.77 \\
\hline 4 & $\begin{array}{l}\text { Memahami instruksi dari dokter atau petugas apotek tentang } \\
\text { cara meminum obat sesuai resepnya? }\end{array}$ & 61.59 & 19.27 \\
\hline 5 & $\begin{array}{l}\text { Mengetahui kapan sebaiknya kamu mencari pendapat dari } \\
\text { dokter lain (second opinion)? }\end{array}$ & 52.89 & 18.77 \\
\hline 6 & $\begin{array}{l}\text { Menggunakan informasi dari dokter untuk mengambil } \\
\text { keputusan tentang penyakit anda? }\end{array}$ & 55.07 & 18.74 \\
\hline 7 & Mengikuti instruksi dari dokter atau petugas apotek? & 65.94 & 15.31 \\
\hline 8 & $\begin{array}{l}\text { Mencari informasi tentang bagaimana mengelola masalah } \\
\text { kesehatan mental seperti stres atau depresi? }\end{array}$ & 56.52 & 16.90 \\
\hline 9 & $\begin{array}{l}\text { Memahami peringatan kesehatan tentang perilaku berisiko } \\
\text { seperti merokok, ngebut, dll? }\end{array}$ & 52.41 & 18.40 \\
\hline 10 & $\begin{array}{l}\text { Memahami mengapa kamu membutuhkan pemeriksaan } \\
\text { kesehatan? }\end{array}$ & 61.83 & 17.34 \\
\hline 11 & $\begin{array}{l}\text { Menilai apakah informasi tentang risiko kesehatan di media } \\
\text { dapat dipercaya? }\end{array}$ & 52.17 & 17.99 \\
\hline 12 & $\begin{array}{l}\text { Menentukan bagaimana kamu dapat melindungi diri dari } \\
\text { penyakit berdasarkan informasi dari media? }\end{array}$ & 53.62 & 17.75 \\
\hline 13 & $\begin{array}{l}\text { Mencari tahu tentang kegiatan-kegiatan yang baik untuk } \\
\text { kesehatan mental anda? }\end{array}$ & 59.17 & 17.56 \\
\hline 14 & $\begin{array}{l}\text { Memahami saran-saran kesehatan dari keluarga dan teman- } \\
\text { teman anda? }\end{array}$ & 65.21 & 17.49 \\
\hline 15 & $\begin{array}{l}\text { Memahami informasi-informasi di media tentang bagaimana } \\
\text { menjadi lebih sehat? }\end{array}$ & 53.14 & 19.58 \\
\hline 16 & $\begin{array}{l}\text { Menilai mana perilaku sehari-hari yang terkait dengan } \\
\text { kesehatan anda? }\end{array}$ & 54.34 & 19.34 \\
\hline
\end{tabular}

Tabel 3. Tingkat Literasi Kesehatan Responden

\begin{tabular}{cc}
\hline \multicolumn{1}{c}{ Variabel Dependen } & Mean (SD) \\
\hline Literasi Kesehatan & $58.4(14.2)$ \\
Literasi Kesehatan Fungsional & $59.6(14.7)$ \\
Literasi Kesehatan Interaktif & $60.5(15.3)$ \\
Literasi Kesehatan Kritikal & $55.6(14.6)$ \\
\hline
\end{tabular}

Berdasarkan tabel 3, rata-rata skor literasi kesehatan pada pasien hipertensi adalah 58,4 $(\mathrm{SD}=14,2)$, dengan skor tertinggi untuk domain literasi kesehatan interaktif, kemudian domain fungsional, dan terendah untuk domain kritikal. Rata-rata skor ini menunjukkan tingkat literasi kesehatan yang rendah pada pasien hipertensi. Hasil ini sejalan dengan penelitian yang dilakukan Soemitro (2014) yang menyatakan bahwa sebagian besar responden memiliki tingkat literasi kesehatan yang buruk. Penelitian oleh Fitriyah
(2017) juga menunjukkan tingkat literasi kesehatan penderita penyakit kronis TB Paru di Kabupaten Sumenep yang sebagian besar masuk dalam kategori sedang dan rendah. Penelitian di fasilitas pelayanan kesehatan primer di negara maju juga menunjukan lebih banyak pasien yang memiliki tingkat literasi kesehatan yang rendah (JovicVranes, Bjegovic-Mikanovic \& Marinkovic, 2009; Shah, West, Brommeyr \& Savoy-Moore, 2010).

Hasil analisis pada Tabel 3 menunjukkan adanya hubungan yang signifikan antara tingkat literasi kesehatan dengan kelompok usia, tingkat pendidikan, status pekerjaan, dan tingkat penghasilan keluarga. Meskipun perempuan memiliki skor literasi kesehatan yang lebih tinggi dari laki-laki, namun perbedaan skornya tidaklah signifikan $(\mathrm{p}=0,477)$. Hal ini menunjukkan bahwa tingkat literasi kesehatan dari pasien hipertensi 
Faletehan Health Journal, 6 (3) (2019) 111-117 www. journal.Ippm-stikesfa.ac.id/ojs/index.php/FHJ ISSN 2088-673X | e-ISSN 2597-8667

tidak dipengaruhi oleh perbedaan jenis kelamin. Penelitian ini sejalan dengan hasil dari penelitianpenelitian terdahulu yang juga menunjukkan bahwa jenis kelamin tidak memiliki hubungan yang signifikan terhadap tingkat literasi kesehatan seseorang (Nasriyanto, 2018; Santosa, 2012). Hasil penelitian juga menunjukkan bahwa tingkat literasi kesehatan secara signifikan dipengaruhi oleh faktor usia, tingkat pendidikan, dan tingkat penghasilan keluarga, namun tidak dipengaruhi oleh status pekerjaan. Dalam penelitian ini, pasien hipertensi yang berusia dewasa (45-55 tahun) memiliki tingkat literasi kesehatan yang lebih baik dari mereka yang berusia lanjut (lebih dari 55 tahun). Pengaruh usia terhadap tingkat literasi kesehatan juga telah ditunjukkan oleh penelitianpenelitian sebelumnya dimana semakin lanjut usia seseorang maka semakin menurun pula tingkat literasi kesehatannya (Murray dkk, 2008; Shah dkk, 2010; Ozdemir dkk, 2010). Usia juga diyakini sebagai faktor yang mempengaruhi kemampuan kognitif seseorang, dimana ketika seseorang memasuki usia lanjut maka ia akan mengalami penurunan fungsi kognitif seperti mengalami kesulitan untuk memahami informasi kesehatan yang diberikan oleh tenaga kesehatan sehingga berdampak pada kemampuan literasi kesehatannya (Ng Edward dan Omariba, 2010; Berens dkk, 2016).

Hasil penelitian pada tabel 4, diketahui bahwa tingkat pendidikan dari pasien hipertensi memiliki hubungan yang signifikan dengan tingkat literasi kesehatannya, dalam hal ini pasien hipertensi yang berpendidikan SMA dan diatasnya memiliki skor literasi kesehatan yang secara signifikan lebih tinggi dari mereka yang berpendidikan SMP dan dibawahnya. Hasil yang menunjukkan asosiasi positif antara tingkat pendidikan dengan tingkat literasi kesehatan ini sejalan dengan yang telah ditunjukkan oleh penelitian sebelumnya (Santosa, 2012; Nazmi dkk, 2015; Ozdemir dkk, 2010). Pendidikan dipercaya dapat mempengaruhi tingkat literasi kesehatan, baik secara langsung maupun tidak langsung. Secara langsung, pendidikan memengaruhi kemampuan dalam membaca, mendengarkan, dan memahami informasi kesehatan, secara tidak langsung, pendidikan berkaitan dengan pekerjaan yang kemudian berdampak pada tingkat ekonomi dan kemampuan finansial untuk menghadapi masalah kesehatan (Ng Edward \& Omariba, 2010).

Tabel 4. Hasil uji determinan sosial terhadap literasi kesehatan $(n=138)$

\begin{tabular}{|c|c|c|c|}
\hline \multirow{2}{*}{ Variabel Independen } & \multicolumn{2}{|c|}{ Bivariat } & \multirow{2}{*}{$\begin{array}{c}\text { Multivariat } \\
\text { B (SE) }\end{array}$} \\
\hline & Mean (SD) & $t$-test & \\
\hline \multicolumn{4}{|l|}{ Jenis Kelamin } \\
\hline Laki-laki & $60,2(11,4)$ & 0,76 & - \\
\hline Perempuan & $57,9(14,8)$ & & \\
\hline \multicolumn{4}{|l|}{ Kelompok Usia } \\
\hline Dewasa (45-55 tahun) & $63,0(13,4)$ & $4,06 * * *$ & ref. \\
\hline Usia lanjut (>55 tahun) & $54,1(13,5)$ & & $-6,1(1,8)^{* *}$ \\
\hline \multicolumn{4}{|l|}{ Tingkat Pendidikan } \\
\hline Rendah $(\leq \mathrm{SMP})$ & $53,2(11,7)$ & $-9,31 * * *$ & ref. \\
\hline Tinggi ( $\geq$ SMA) & $73,2(9,3)$ & & $12,5(2,43) * * *$ \\
\hline \multicolumn{4}{|l|}{ Status Pekerjaan } \\
\hline Tidak bekerja & $55,5(12,9)$ & $-4,55 * * *$ & ref. \\
\hline Bekerja & $67,7(14,3)$ & & $-3,04(2,27)$ \\
\hline \multicolumn{4}{|l|}{ Tingkat Penghasilan Keluarga } \\
\hline Rendah ( $\leq$ UMR Kota Cilegon) & $53,2(12,6)$ & $-7,29 * * *$ & ref. \\
\hline Tinggi ( $\geq$ UMR Kota Cilegon) & $69,3(10,9)$ & & $9,1(2,23)^{* * *}$ \\
\hline
\end{tabular}


Penelitian juga menunjukkan hubungan yang signifikan antara tingkat penghasilan keluarga pasien hipertensi dengan tingkat literasi kesehatannya, dimana pasien yang memiliki penghasilan keluarga di atas UMR Kota Cilegon diketahui memiliki skor literasi kesehatan yang secara signifikan lebih tinggi dari mereka yang penghasilan keluarganya di bawah UMR. Hasil yang menunjukkan asosiasi positif antara tingkat penghasilan dengan tingkat literasi kesehatan ini sejalan yang telah ditunjukkan oleh penelitian sebelumnya (Ozdemir dkk, 2010). Tingkat ekonomi diketahui mempengaruhi kemampuan untuk mendapatkan pendidikan dan pelayanan kesehatan, sehingga pada akhirnya mempengaruhi kemampuan dalam memperoleh, memahami dan menggunakan informasi kesehatan (Ferguson \& Pawlak, 2011).

Uji analisis penelitian menunjukkan hubungan yang signifikan antara status pekerjaan dengan tingkat literasi kesehatan, namun kekuatan hubungannya berubah setelah dikontrol dengan variabel usia, tingkat pendidikan, dan tingkat penghasilan keluarga. Hasil ini menunjukkan bahwa hubungan antara pekerjaan pasien hipertensi dengan tingkat literasi kesehatannya tidaklah independen, tetapi dipengaruhi oleh faktor lain yang memang diketahui berhubungan langsung dengan literasi kesehatan, seperti pendidikan dan penghasilan ( $\mathrm{Ng}$ Edward \& Omariba, 2010).

\section{Simpulan}

Penelitian ini menunjukkan bahwa tingkat literasi kesehatan pada pasien hipertensi yang berobat di delapan puskesmas di Kota Cilegon umumnya berada pada kategori rendah. Adapun determinan yang berpengaruh pada tingkat literasi kesehatan dari pasien hipertensi dalam penelitian ini adalah usia, pendidikan, dan penghasilan.

\section{Referensi}

Berens, E. M., Vogt, D., Messer, M., Hurrelmann, K., \& Schaeffer, D. (2016). Health literacy among different age groups in Germany: results of a cross-sectional survey. $B M C$ Public Health, 16(1), 1-8. http://doi.org/10.1186/s12889-016-3810-6

Badan Penelitian dan Pengembangan Kesehatan. (2018). Riset Kesehatan Dasar 2018. Jakarta: Kementerian Kesehatan Republik Indonesia.

Berkman, N. D., Sheridan, S. L., Donahue, K. E.,
Halpern, D. J., \& Crotty, K. (2011). Low Health Literacy and Health Outcomes: An Updated Systematic Review. Annals of Internal Medicine, 155(2), 97. http://doi.org/10.7326/0003-4819-155-2201107190-00005

Dinas Kesehatan Kota Cilegon. (2017). Profil Kesehatan Kota Cilegon Tahun 2017.

Ferguson, L. A., \& Pawlak, R. (2011). Health Literacy: The road to improved health outcomes. The Journal for Nurse Practitioners, $\quad 7(2)$, 123-129. http://doi.org/http://dx.doi.org/10.1016/j.nurp ra.2010.11.020

Fitriyah (2017). Literasi Kesehatan pada Penderita Penyakit Kronis TB Paru di Kabupaten Sumenep. (Skripsi). Repositori Universitas Airlangga.

Hastono, S. P. (2016) Analisa Data pada Bidang Kesehatan. Jakarta: Raja Grafindo

Institute Of Medicine of The National Academic (2012) Health Literacy: A Prescription to End Confusion, Annals of Vascular Surgery. doi: 10.1016/j.avsg.2011.11.037.

Jovic-Vranes, A., Bjegovic-Mikanovic, V., \& Marinkovic, J. (2009). Functional health literacy among primary health-care patients: data from the Belgrade pilot study. Journal of Public Health, 31(4), 490-495. http://doi.org/10.1093/pubmed/fdp049

Kementerian Kesehatan. (2013). Pedoman Teknis Penemuan Dan Tatalaksana Hipertensi. Jakarta: Kementerian Kesehatan Republik Indonesia.

Lee, S.D. Tsai TI, Tsai Y.W \& Kuo, KN (2010) Health Literacy, Health status and healthcare utilization of taiwan adults: results from a national survey. BMC Public Health, 10. 614

Lee, H. Y., Choi, J.-K., \& Lee, M. H. (2015). Health literacy in an underserved immigrant population: New implications toward achieving health equity. Asian American Journal of Psychology, 6(1), 97-105. https://doi.org/10.1037/a0037425

Murray, T.S., Hagey, J., Willms, D., Shillington, R., dan Desjardins, R. (2008) Health literacy in Canada: a healthy understanding. Ottawa, CA: Canadian Council on Learning.

Nazmi, N., Rudolfo, G., Restila, R. Emytri, E. (2015). Faktor-faktor yang mempengaruhi literasi kesehatan di fasilitas pelayanan kesehatan: systematic review. Prosiding 
Faletehan Health Journal, 6 (3) (2019) 111-117 www. journal.Ippm-stikesfa.ac.id/ojs/index.php/FHJ ISSN 2088-673X | e-ISSN 2597-8667

Seminar Nasional Penelitian dan Pengabdian Masyarakat, Universitas Islam Bandung.

Ng, Edward., Walter, D., \& Omariba, R. (2010). Health Literacy and immigrants in Canada: Determinants and effects on health outcomes. Ottawa. Retrieved from https://pdfs.semanticscholar.org/7f7d/78e6f2f 0e183a02adee41ce1989a3fc2c714.pdf

Nasriyanto, E. N. (2018). Pengaruh Determinan Sosial Terhadap Tingkat Literasi Kesehatan Pada Mahasiswa Universitas Indonesia di Kota Depok. (Tesis). Repositori Universitas Indonesia.

Ozdemir, H., Alper, Z., Uncu, Y., \& Bilgel, N. (2010). Health literacy among adults: a study from Turkey. Health Education Research, 25(3), 464-477. http://doi.org/10.1093/her/cyp068

Santosa, K.M. (2012). Faktor-faktor yang berhubungan dengan tingkat kemelekan kesehatan pasien di klinik dokter keluarga Fakultas Kedokteran Universitas Indonesia Kiara DKI Jakarta. (Tesis). Repositori Universitas Indonesia.

Shah, L. C., West, P., Bremmeyr, K., \& SavoyMoore, R. T. (2010). Health literacy instrument in family medicine: the newest vital sign ease of use and correlates. Journal of the American Board of Family Medicine, 23(2),

195-203. http://doi.org/10.3122/jabfm.2010.02.070278
Soemitro, D. H. (2014). Analisis Tingkat Health Literacy dan Pengetahuan Pasien Hipertensi di Puskesmas Kabupaten Malang. (Skripsi). Repositori Universitas Surabaya.

Sørensen, K., Van den Broucke, S., Fullam, J., Doyle, G., Pelikan, J., Slonska, Z., \& Brand, H. (2012). Health literacy and public health: a systematic review and integration of definitions and models. BMC Public Health, 12, 80. http://doi.org/10.1186/1471-2458-1280

Storms, H., Claes, N., Aertgeerts, B., \& Van den Broucke, S. (2017). Measuring health literacy among low literate people: an exploratory feasibility study with the HLS-EU questionnaire. BMC Public Health, 17(1), 475. http://doi.org/10.1186/s12889-0174391-8

Weiss, B.D. (2007) Health Literacy and Patient's Safety: Help patients Understand manual for Clinicians $2^{\text {nd }}$ edition. Chicago: American Medical Association Foundation.

World Health Organization. (2015). Raised Blood Pressure. Geneve: World Health Organization. Diakses dari http://www.who.int/gho/ncd/risk_factors/blo od_pressure_prevalence_text/en/ 